\title{
Community empowerment through making maroca (mangrove root craft) in village Tanjung Rejo, Kecamatan Percut Sei Tuan, Sumatera Utara
}

\author{
Ipanna Enggar Susetya ${ }^{1 *}$, Astrid Fauzia Dewinta ${ }^{1}$, Ridahati Rambey $^{2}$, Sudiati $^{3}$, Azhari $^{3}$, Mai \\ Suriani ${ }^{4}$ \\ ${ }^{1}$ Program Studi Manajemen Sumberdaya Perairan, Fakultas Pertanian Universitas Sumatera \\ Utara \\ ${ }^{2}$ Fakultas Kehutanan, Universitas Sumatera Utara \\ ${ }^{3}$ Fakultas MIPA, Universitas Sumatera Utara \\ ${ }^{4}$ Program Studi Ilmu Kelautan, Fakultas Perikanan dan Ilmu Kelautan, Universitas Teuku Umar \\ *Email: ipanna@usu.ac.id
}

\begin{abstract}
Mangrove ecosystems in Tanjung Rejo Village, Percut Sei Tuan Sub-district, Deli Serdang experienced a lot of land conversion in the form of residential, agricultural and plantation lands. This causes abrasion in this region because there is no protection from waves and sea waves in this region. Land conversion and abrasion caused many mangrove trees to die. Mangrove trees that died were only used on the trunk, twigs and leaves by local residents. Many parts of the dead mangrove roots are not utilized. This community service activity aims to provide information and skills to partner groups about the making of MAROCA. Through this activity, partners will gain knowledge and skills in making MAROCA so that materials that are not initially valuable like dead mangrove roots become useful. Based on the description of the problem and the purpose of this community service activity, the activities that have been carried out are counseling about the manufacturing of MAROCA, giving leaflets for the procedures for making and providing tools and materials. The results obtained are increased knowledge and skills of partners about the benefits of dead mangrove roots as economically valuable handicrafts.
\end{abstract}

Keyword: crafts, roots, mangrove, maroca

\begin{abstract}
Abstrak
Ekosistem mangrove di Desa Tanjung Rejo Kecamatan Percut Sei Tuan, Deli Serdang banyak mengalami konversi lahan berupa lahan pemukiman, pertanian dan perkebunan. Hal ini menyebabkan terjadinya abrasi di wilayah ini karena tidak ada pelindung dari ombak dan gelombang laut di wilayah ini. Konversi lahan dan abrasi menyebabkan banyak pohon mangrove yang mengalami kematian. Pohon mangrove yang mati tersebut hanya dimanfaatkan pada bagian batang, ranting maupun daun oleh penduduk setempat. Bagian akar mangrove mati banyak yang tidak dimanfaatkan.Kegiatan pengabdian masayarakat ini bertujuan untuk memberikan informasi dan ketrampilan kepada kelompok mitra tentang pembuatan MAROCA. Melalui kegiatan ini, mitra akan mendapat pengetahuan dan ketrampilan dalam membuat MAROCA sehingga bahan-bahan yang awalnya tidak bernilai seperti akar mangrove yang sudah mati menjadi bermanfaat. Berdasarkan uraian permasalahan dan tujuan dari kegiatan pengabdian masayarakat ini, maka kegiatan yang telah dilakukan adalah penyuluhan tentang pembuatan MAROCA, pemberian leaflet tata cara pembuatan dan pemberian alat dan bahan. Hasil yang diperoleh adalah bertambahnya pengetahuan dan ketrampilan mitra tentang manfaat akar mangrove yang sudah mati sebagai bahan kerajinan tangan yang bernilai ekonomis.
\end{abstract}

Kata Kunci : kerajinan, akar, mangrove, maroca,

\section{PENDAhuluan}

Mangrove adalah kelompok taksonomi vegetatif yang beragam, toleran terhadap salinitas perairan yang beragam, dan tumbuh terutama di daerah tropis dan subtropis (Ellison dan Stoddart, 1991). Ekosistem mangrove merupakan suatu sistem ekologi yang terdiri atas organisme yang berinteraksi dengan faktor lingkungan. Secara fisik, hutan mangrove dapat berfungsi mencegah abrasi dan intrusi 
air laut, menjaga garis pantai agar stabil, perlindungan pemukiman dari angin laut, menangkap dan melokalisasi sedimen dan menyaring limbah (Dahdouh-Guebas and Koedam, 2006). Secara ekologi, mangrove berfungsi sebagai tempat pemijahan (spawning ground), pengasuhan (nursery ground) dan mencari makan (feeding ground) bagi berbagai jenis hewan (Hogarth, 2007). Saat ini banyak terjadi permasalahan di ekosistem mangrove seperti penebangan pohon mangrove secara liar, kebakaran hutan dan konversi lahan.

Konversi lahan mangrove banyak terjadi di Sumatera Utara. Ekosistem mangrove di provisnsi ini berubah menjadi pemukiman, tambak, perkebunan dan pertanian, dan lain-lain. Salah satu lokasi yang telah terjadi konversi lahan dari ekosistem mangrove menjadi lahan lain adalah di Desa Tanjung Rejo Kecamatan Percut Sei Tuan Kabupaten Deli Serdang. Hal ini menyebabkan penurunan fungsi ekosistem mangrove baik secara fisik, ekologi dan ekonomi. Wilayah pesisir desa ini juga terkena abrasi parah karena konversi lahan tersebut. Berkurangnya pelindung pantai yang alami (amngrove) menjadi penyebab abrasi parah di desa tersebut.

Wilayah Percut Sei Tuan memiliki luas 190,79 $\mathrm{km}^{2}$ dengan persentase penggunaan lahan terbesar adalah persawahan, perkebunan, irigasi, pemukiman dan sebagian lahan basah. Penggunaan lahan untuk kegiataan persawahan seluas $9.761 \mathrm{Ha}$ atau 32,0\% perkebunan seluas $6.074 \mathrm{Ha}$ $(19,92 \%)$, irigasi $2,582 \mathrm{Ha}(8,47 \%)$, pemukiman seluas $4.785 \mathrm{Ha}(15,69 \%)$, dan lahan basah seluas $2.709 \mathrm{Ha}(8,8 \%$ ) (Monografi Kecamatan Percut Sei Tuan, 2004).

Alih fungsi lahan mangrove menjadi pemukiman, pertambakan, perkebunan dan pertanian menyebabkan penurunan kualitas dan kuantitas ekosistem mangrove. Peranan mangrove salah satunya peranan secara fisik sebagai pelindung daerah pesisir dari ombak dan gelombang air laut menjadi berkurang. Akibatnya terjadi abrasi di Desa Tanjung Rejo, Kecamatan Sei Tuan. Permasalahan ekosistem mangrove di desa ini menyebabkan banyak pohon mangrove yang mengalami kematian. Pohon mangrove yang mati tersebut hanya dimanfaatkan pada bagian batang, ranting maupun daun oleh penduduk setempat. Bagian akar mangrove yang mati ditinggalkan dan tidak dimanfaatkan.

Mitra kegiatan pengabdian skim Dosen Wajib Mangabdi 2019 saat ini adalah kelompok penggiat rehabilitasi lahan mangrove di Desa Tangjung Rejo, Kecamatan Percut Sei Tuan. Mitra pengabdian sebagian besar bekerja di lahan pertanian dan perkebunan di desa tersebut. Untuk meningkatkan pengetahuan, ketrampilan dan perekonomian mitra sehingga kegiatan ini dilakukan. Latar belakang dilakukannya kegiatan pengabdiaan ini juga untuk meningkatkan nilai jual akar mangrove mati yang tidak dimanfaatkan penduduk sekitar menjadi barang bernilai ekonomis.

\section{METODE PELAKSANAAN}

Metode pelaksanaan kegiatan pengabdian masyarakat dilakukan adalah penyuluhan atau sosialisasi dan pelatihan pembuatan Maroca (Mangrove Root Craft). Pendekatan tersebut diharapkan dapat meningkatkan kesadaran masyarakat khususnya nelayan mitra kegiatan tentang cara budidaya Ikan Lele sekaligus kangkung yang efektif dan efisien dalam wadah ember.

\subsection{Penyuluhan}

Kegiatan yang pertama kali dilakukan adalah penyuluhan dengan metode diskusi dengan narasumber. Selama kegiatan berlangsung peserta atau mitra pengabdian dapat melakukan tanya jawab dengan narasumber. Tujuan kegiatan ini adalah untuk memberikan informasi dan pengetahuan tentang bahan dan cara-cara pembuatan Maroca.

\subsection{Pelatihan Pembuatan Maroca}

Melalui kegiatan pelatihan, mitra pengabdian diberikan kesempatan untuk praktek membuat Maroca secara langsung dengan narasumber. Hal ini dilakukan dengan tujuan agar mitra pengabdian memiliki ketrampilan dalam memanfaatkan akar mangrove mati yang selama ini tidak dimanfaatkan oleh penduduk sekitar. 


\section{HASIL DAN PEMBAHASAN}

Kegiatan pengabdian kepada masyarakat diawali dengan penawaran kerjasama dengan mitra pengabdian di Desa Percut Sei Tuan yang diketuai oleh Bapak Prayetno. Hasil dari penawaran kerjasama kegiatan pengabdian ini adalah sambutan baik dan dukungan dari mitra dengan memberikan surat kesediaan kerja sama. Adanya surat kerjasama ini menjadi modal awal untuk mengajukan proposal kegiatan pengabdian. Proposal yang telah dibuat dengan judul "Pemberdayaan Masyarakat melalui Pembuatan Maroca (Mangrove Root Craft) di Desa Tanjung Rejo, Kecamatan Percut Sei Tuan, Sumatera Utara" kemudian diajukan kepada Lembaga Pengabdian Masyarakat Universitas Sumatera Utara. Hasil dari pengajuan proposal ini adalah persetujuan pihak LPM Universitas Sumatera Utara untuk melaksanakan kegiatan ini.

\subsection{Penyuluhan}

Kegiatan penyuluhan dihadiri oleh tim kegiatan pengabdian masyarakat, narasumber serta mitra pengabdian masyarakat yang terdiri dari bapak-bapak dan ibu-ibu dari penggiat rehabilitasi lahan mangrove di Desa Tangjung Rejo, Kecamatan Percut Sei Tuan.Pelaksanaan penyuluhan dilakukan di rumah narasumber kegiatan pengabdian yaitu Bapak Paisal Amin Nasution. Materi yang disampaikan berkaitan tentang pembuatan Maroca dari pemilihan bahan, alat-alat yang digunakan, tahapan pembuatan dari awal sampai akhir. Kegiatan sosialisasi ini bermanfaat untuk menyampaikan informasi tentang pemanfaatan akara mengrove mati menjadi bahan kerajinan yang memiliki nilai ekonomis (Gambar 3.1) .

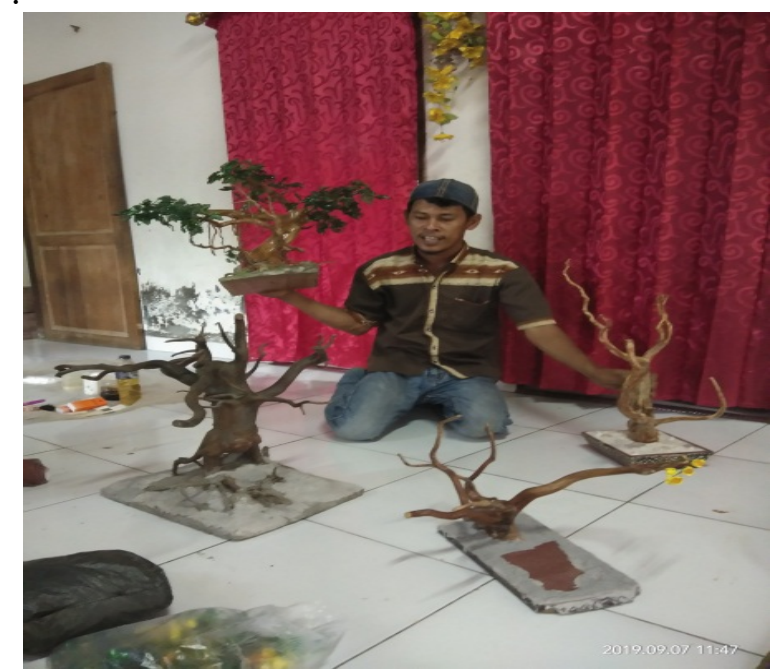

Gambar 3.1. Kegiatan penyuluhan

\subsection{Prosedur Pembuatan Maroca}

Alat dan Bahan. Akar mangrove yang sudah mati,amplas kayu, kuas, pernis, lem G, bor ayu, gunting, pernis, daun dan bunga akrilik (plastik sesuai selera), pot dan semen (jika ingin dibuat model bonsai). Alat dan bahan yang digunakan dapat dilihat pada Gambar 3.2. 


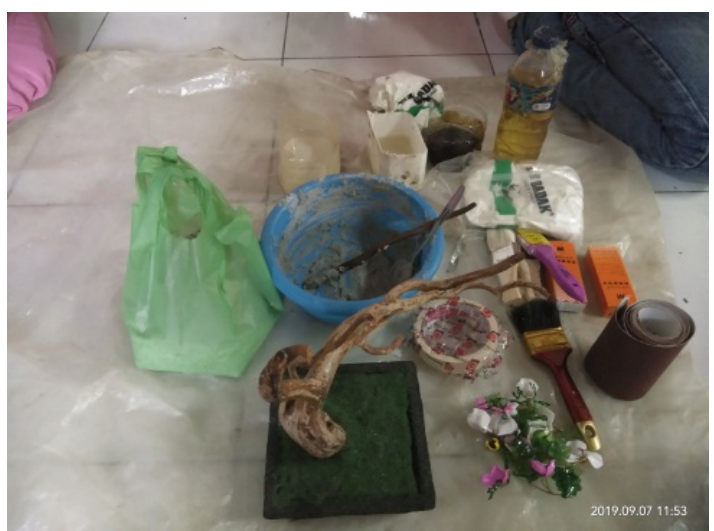

Gambar 3.2. Alat dan bahan Maroca

Cara Pembuatan

- Siapkan akar mangrove yang sudah mati

- Cuci akar mangrove agar bersih dari pasir dan lumpur

- Keringkan akar yang sudah djemur di bawah sinar matahari

- Setelah kering, haluskan permukaan akar dengan cara mengamplasnya.

- Siapkan pot, kemudian diisi adonan semen sebagai dasar melekatkan akar mangrove (jika ingin dibentuk bonsai, jika dibuat hiasan dinding tidak perlu pot dan semen).

- Akar mangrove diletakkan pada pot dengan posisi terbalik agar terlihat seperti bentuk pohon bonsai karena cabang-cabang akar mangrove menjadi cabang pohon.

- Setelah kering dan akar mangrove menempel kuat pada pot, lubangi kecil-kecil pada beberapa bagian cabang akarnya menggunakan bor kayu sebagai tempat ditempelkan daun dan bunga.

- Oleskan pernis atau plitur agar akar terlihat mengkilap dan dibiarkan sampai kering.

- Tempelkan daun dan bunga yang sudah dibentuk dengan kawat pada lubang yang telah disediakan menggunakan lem $\mathrm{G}$.

\subsection{Pelatihan Pembuatan Maroca}

Pelatihan pembuatan Maroca dilakukan dengan memberikan alat dan bahan kepada mitra pengabdian. Bahan pelatihan berupa akar mangrove yang telah mati diberikan dalam kondisi masih alami dari alam (belum dilakukan perlakuan). Hal ini dimaksudkan agar mitra mengetahui seluruh tahap pembuatan. Akar yang digunakan harus dari tanaman yang sudah mati dan tidak diperbolehkan dari pohon yang masih hidup (Gambar 3.3). Alasannya yang pertama adalah untuk menjaga ekosistem mangrove di Desa Tanjung Rejo dan yang kedua karena kualitas akar dari pohon yang mati lebih baik daripada akar dari pohon yang masih hidup. Bapak Paisal Amin Nasution selaku narasumber pelatihan mengatakan bahwa, akar dari pohon yang masih hidup masih banyak serbuknya (rayap atau organisme lain).

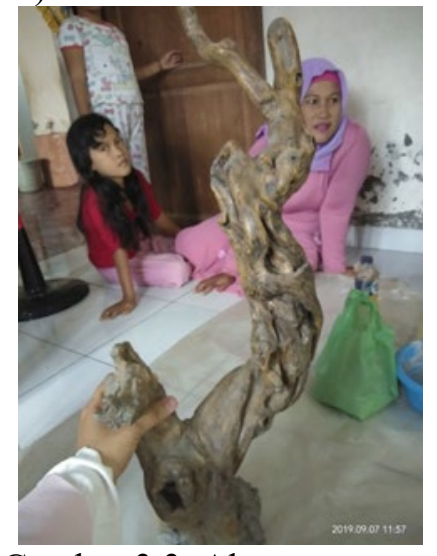

Gambar 3.3. Akar mangrove 
Tahap selanjutnya yang dilakukan oleh mitra pengabdian setelah mendapatkan bahan akar mangrove adalah melaksanakan prosedur pembuatan mulai dari pembersihan dan pengeringan akar, pembuatan dasar kerajinan yang berupa bonsai, pengeboran akar mangrove, pengecatan akar dengan pernis dan terakhir pemasangan daun dan bunga pada akar (Gambar 3.4 dan 3.5).

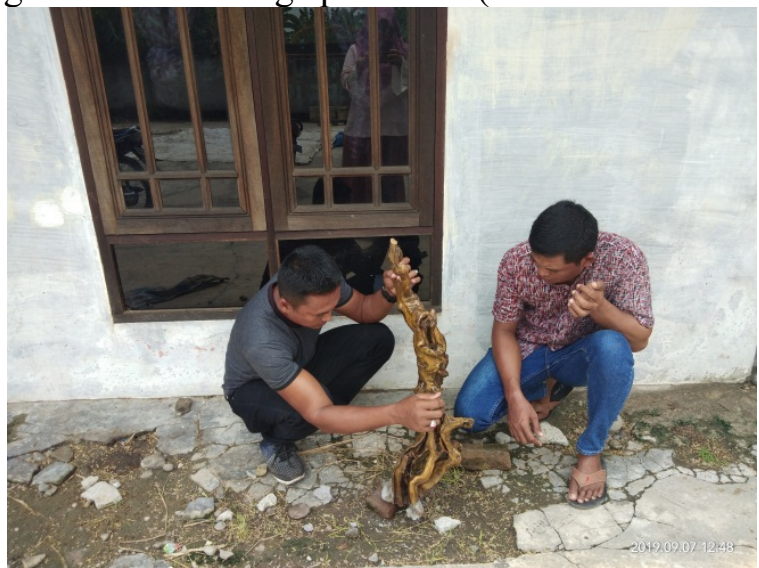

Gambar 3.4. Pemberian pernis pada akar

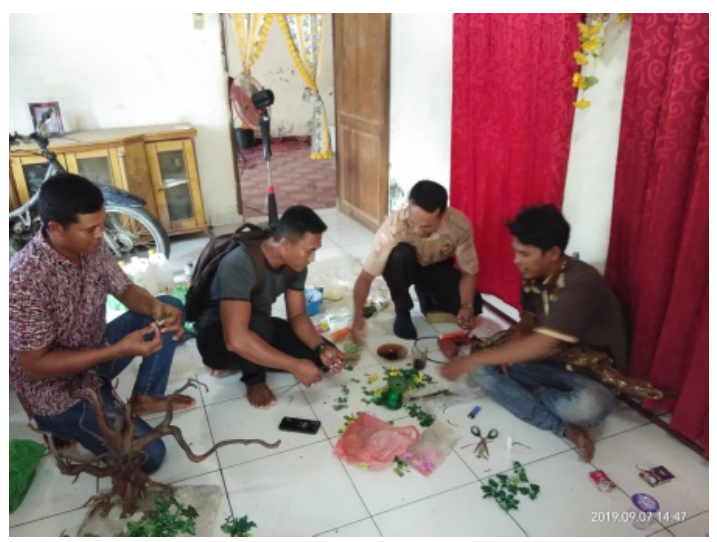

Gambar 3.5. Pemasangan daun serta bunga akrilik pada akar mangrove

\subsection{Hasil Pembuatan}

Hasil dari pelatihan pembuatan kerajinan dari akar mangrove yang sudah mati berupa hiasan dinding (Gambar 3.6) dan bonsai (Gambar 3.7) yang diberikan nama Maroca (Mangrove Root Craft).

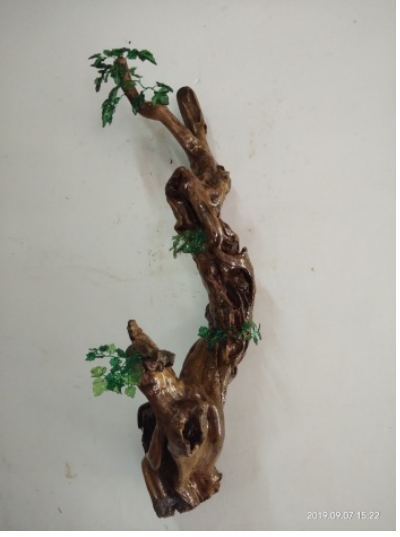

Gambar 3.6. Maroca berbentuk hiasan dinding 


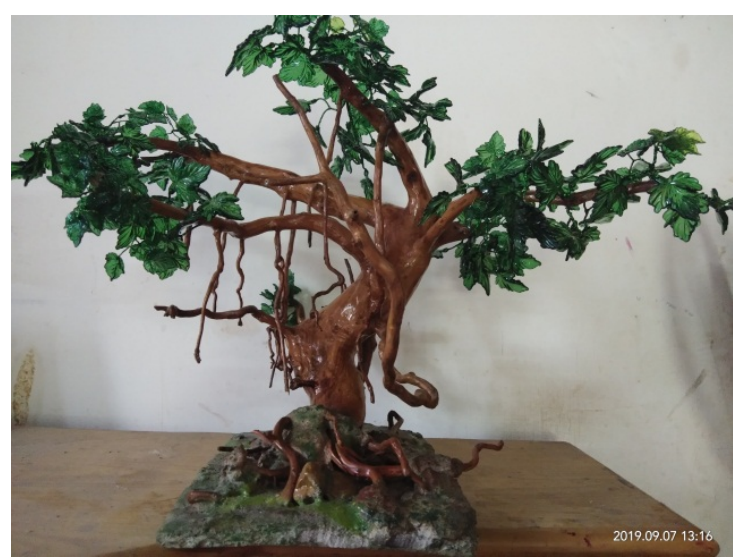

Gambar 3.7. Maroca berbentuk bonsai

\section{KESIMPULAN DAN SARAN}

\subsection{Kesimpulan}

Rangkaian kegiatan pengabdian masyarakat yang telah dilakukan adalah penyuluhan, pemberian alat dan bahan sampai praktek pembuatan Maroca.

\subsection{Saran}

Kegiatan pengabdian diharapkan tidak hanya dilakukan di Desa Tanjung Rejo, Kecamatan Sei Tuan tetapi di lokasi lain supaya masyarakat mendapat ketrampilan dalam memanfaatkan barang yang tidak bernilai menjadi barang yang memiliki nilai ekonomis. Kerajinan yang dibuat juga bisa diterapkan pada akar pohon selain pohon mangrove.

\section{UCAPAN TERIMAKASIH}

Ucapan terima kasih penulis berikan kepada Universitas Sumatera Utara yang telah mendanai kegiatan pengabdian kepada masyarakat melalui dana NON PNBP Universitas Sumatera Utara. Sesuai dengan Surat Perjanjian Penugasan Pelaksanaan Pengabdian kepada Masyarakat Program Dosen Mengabdi Tahun Anggaran 2019 Nomor: 788/UN5.2.3.2.1/PPM/2019, Tanggal 23 Juli 2019. Penulis juga mengucapkan terima kasih kepada mitra kegiatan pengabdian masyarakat yang diketuai oleh Bapak Prayetno dan narasumber penyuluhan Bapak Paisal Amin Nasution

\section{DAFTAR PUSTAKA}

Dahdouh-Guebas, F. dan N. Koedam. (2006). Coastal vegetation and the Asian tsunami. Science $311,37-38$.

Data Potensi Desa Tanjung Rejo Tahun. (2003). Badan Pusat Statistik, Kota Medan Dalam Angka.

Ellison, J.C. dan D.R. Stoddart. (1991). Mangrove ecosystem collapse during predicted sea-level rise: Holocene analogues and implications. Journal of Coastal Research, 7: 151-165.

Hogarth, P.J. 2007. The Biology of Mangroves. Oxford University Press Inc: New York 